UNIVERSIDADE ESTADUAL DE FEIRA DE SANTANA

Autorizada pelo Decreto Federal $n^{0} 77.496$ de 27/04/76

Recredenciamento pelo Decreto $n^{\circ} 17.228$ de 25/11/2016

PPPCÓ-REITORIA DE PESQUISA E PÓS-GRADUAÇÃo

PPPG) COORDENAÇÃo de INICIAÇÃo CIENTÍFICA

XXIV SEMINÁRIO DE INICIAÇÃO CIENTÍFICA DA UEFS

SEMANA NACIONAL DE CIÊNCIA E TECNOLOGIA - 2020

\title{
MAPEAMENTO DOS GEOSSÍTIOS DO MUNICÍPIO DE ITAETÊ, INSERIDOS EM REGIÃO POTENCIAL A GEOPARQUE
}

\author{
SILVA, Ericka Medeiros; SILVA, Ardemírio de Barros²; SOUZA, Deorgia \\ Tayane Mendes ${ }^{3}$. \\ 1. Bolsista FAPESB, Graduanda em Licenciatura em Geografia, Universidade Estadual de Feira de Santana, e-mail: \\ medeirosericka05@gmail.com \\ 2. Orientador, Departamento de Ciências Exatas, Universidade Estadual de Feira de Santana, e-mail: abarros@uefs.br \\ 3.Co-orientadora, Departamento de Ciências Exatas, Universidade Estadual de Feira de Santana, e-mail: \\ deorgiasouza.geo@gmail.com
}

PALAVRAS-CHAVE: Geossítio; Mapeamento; Sensoriamento Remoto.

\section{INTRODUÇÃO}

Os elementos da geodiversidade, tais como a geologia, geomorfologia e pedologia são peças-chave para entender a evolução da terra e da vida. Quando inventariados e dotados de valores científicos e/ou turístico e/ou educativo, e bem delimitados geograficamente, são consagrados como geossítios (BRILHA, 2012). Definir uma rede local de geossítios, com limites definidos, apresentando estratégias de geoconservação, desenvolvimento sustentável e multidisciplinar da região, dialogando com a (s) comunidade (s) locais e boa estrutura de gestão, viabiliza a implantação de um Geoparque. Este trabalho tem o objetivo de georreferenciar e fazer a caracterização geoambiental de três geossítios do município de Itaetê: a Caverna do Poço Encantado, a Caverna da Lapa do Bode e a Cachoeira Encantada, que em 2010 esteve em um perímetro em avaliação para o Geoparque Chapada Diamantina pela CPRM e também proposta por Pereira (2010).

\section{METODOLOGIA}

O georreferenciamento da caverna do Poço Encantado e Lapa do Bode foram feitos em trabalho de campo, com uso de um aparelho de GPS, o Garmim Portátil Gpsmap 64s. A Cachoeira Encantada foi georreferenciada por meio do programa Google Earth. Durante a atividade de campo, em parceria com o Programa Mandacarú que estava desenvolvendo projetos educacionais por meio de Diagnósticos Rurais Participativos no município junto com a Universidade Federal do Recôncavo da Bahia (UFRB), foram visitados assentamentos próximos aos geossítios, para conhecer algumas de suas atividades econômicas e base educacional, o que são elementos fundamentais para estratégias de geoeducação, geoconservação e geoturismo nos geossítios, e para projetos de implantação do geoparque. 
A caracterização geoambiental foi feita a partir da elaboração de mapas geológico, geomorfológico e pedológico, a partir de arquivos shapefiles obtidos na base de dados do IBGE, em escala 1:250.00. Para o levantamento de informações topográficas e de declividade, utilizou-se um Modelo Digital de Elevação (MDE), oriundo da mosaicagem de três imagens de radar do satélite ALOS (Advanced Land Observing Satellite) sensor PALSAR, com resolução espacial de 12,5 metros, duas delas datadas de 17/10/2011 e outra de 31/10/2010 que cobre uma pequena porção leste do município, adquiridas gratuitamente no sistema Alaska Satellite Facility, operado e distribuído pelo Earth Data/National Aeronautics and Space Administration (NASA, acrônimos em inglês). Os procedimentos foram realizados por meio de técnicas de Sensoriamento Remoto e Sistema de Informação Geográfica (SIG), com uso do software ArcGIS 10.1.

\section{RESULTADOS E DISCUSSÃO}

O quadro 1 apresenta a localização dos geossítios Caverna do Poço Encantado, Lapa do Bode e a Cachoeira Encantada sobre a superfície da Terra, por meio das coordenadas métricas do Sistema Universal Transversa de Mercator (UTM).

Quadro 1-Geossítios e suas respectivas coordenadas.

\begin{tabular}{|c|c|}
\hline GEOSSÍTIOS & $\begin{array}{c}\text { COORDENADAS } \\
\text { Caverna do Poço Encantado }\end{array}$ \\
\hline Caverna da Lapa do Bode & $8667930 \mathrm{mN} / 271598 \mathrm{mE}$ \\
\hline Cachoeira Encantada & $8569011 \mathrm{mN} / 275845 \mathrm{mE}$ \\
\hline & $8265238 \mathrm{mN} / 265238 \mathrm{mE}$ \\
\hline
\end{tabular}

A partir da definição de geodiversidade apresentadas por Gray (2004) e pela CPRM (2006) gerou-se mapas representativos dos seus diferentes elementos (geologia, geomorfologia e pedologia), no recorte do município de Itaetê, com ênfase nos geossítios nele inserido (Fig. 1).

Constata-se que os geossítios encontram-se em bacias sedimentares, com a Caverna do Poço Encantado e a Gruta Lapa do Bode inseridas em litologias Neoproterozóicas da Formação Salitre, representada por uma plataforma carbonática do Grupo Una, e o geossítio Cachoeira Encantada compreendido em litologias Mesoproterozóicas da Formação Tombador, do Grupo Chapada Diamantina (Fig. 1 - A).

Como ilustra a figura 1 - B e D, as rochas carbonáticas do Grupo Una sustentam um planalto de relevo ondulado, com baixos platôs, cujas altitudes mais baixas são registradas ao longo do Rio Una. Segundo Pereira (1998), esse planalto carbonático apresenta uma paisagem de relevo cárstico. Na borda leste do planalto delineado por uma face escarpada, as altitudes decrescem, de $700 \mathrm{~m}$ a $263 \mathrm{~m}$, registrados ao longo do Vale do Rio Paraguaçu, em superfícies aplainadas degradadas de natureza ígnea e metamórfica, com rochas residuais denominadas de inselbergs. À oeste do planalto é marcada pelo contraste de relevo sustentado pelo Grupo Chapada Diamantina, cujos topos variam entre $1470 \mathrm{~m}$ e $400 \mathrm{~m}$, com escarpas, degraus estruturais e rebordos erosivos, a qual está inserida a Cachoeira Encantada.

A caverna do Poço Encantado está inserida em um contexto de relevo plano a forteondulado; a caverna Lapa do Bode é delimitada a leste por uma face íngreme até ao topo, que suaviza à um relevo ondulado para oeste, com ocorrência de terrenos planos nas proximidades; $\mathrm{O}$ rio Timbozinho tem o seu curso d’água em relevos de caráter 
montanhoso a plano, com a queda d'água de um relevo plano, em desnível acentuado de 100m, entre escarpas, que caracteriza a Cachoeira Encantada (Fig. 1 - E).
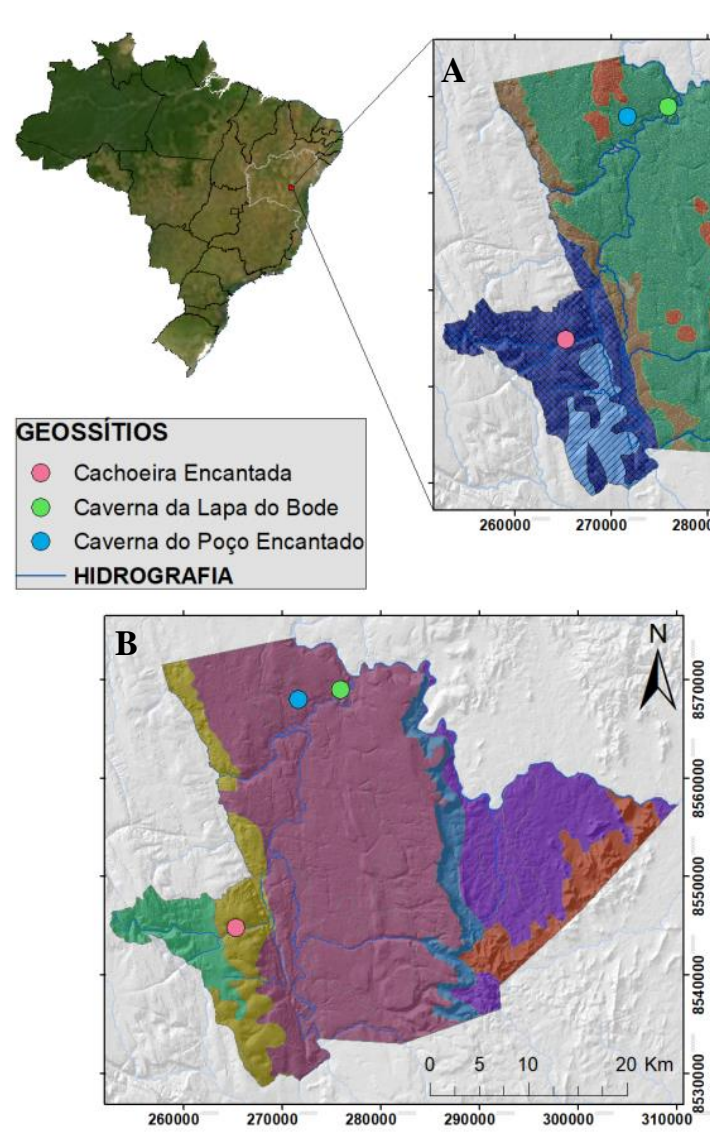

RELEVO
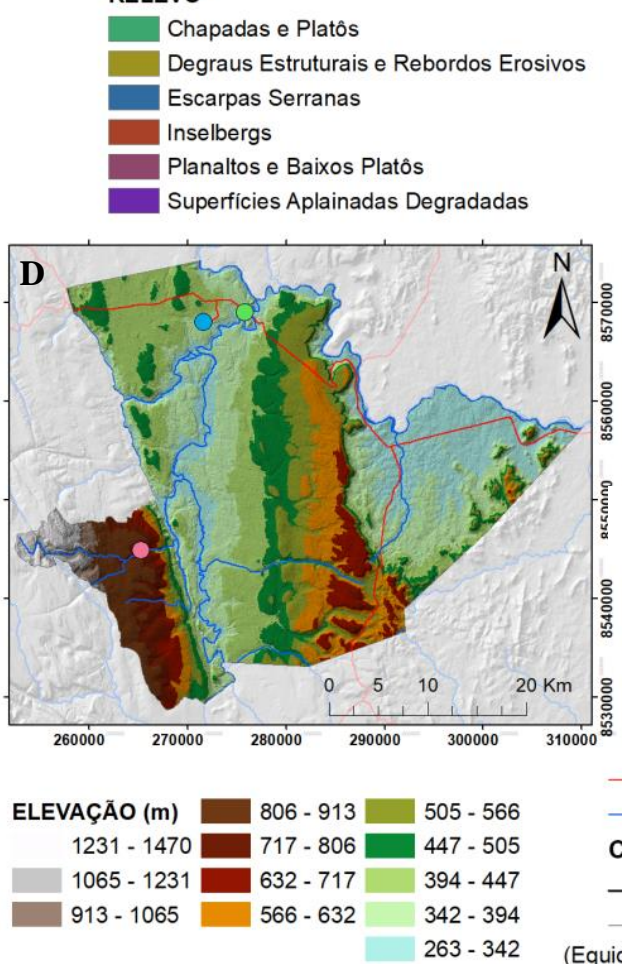
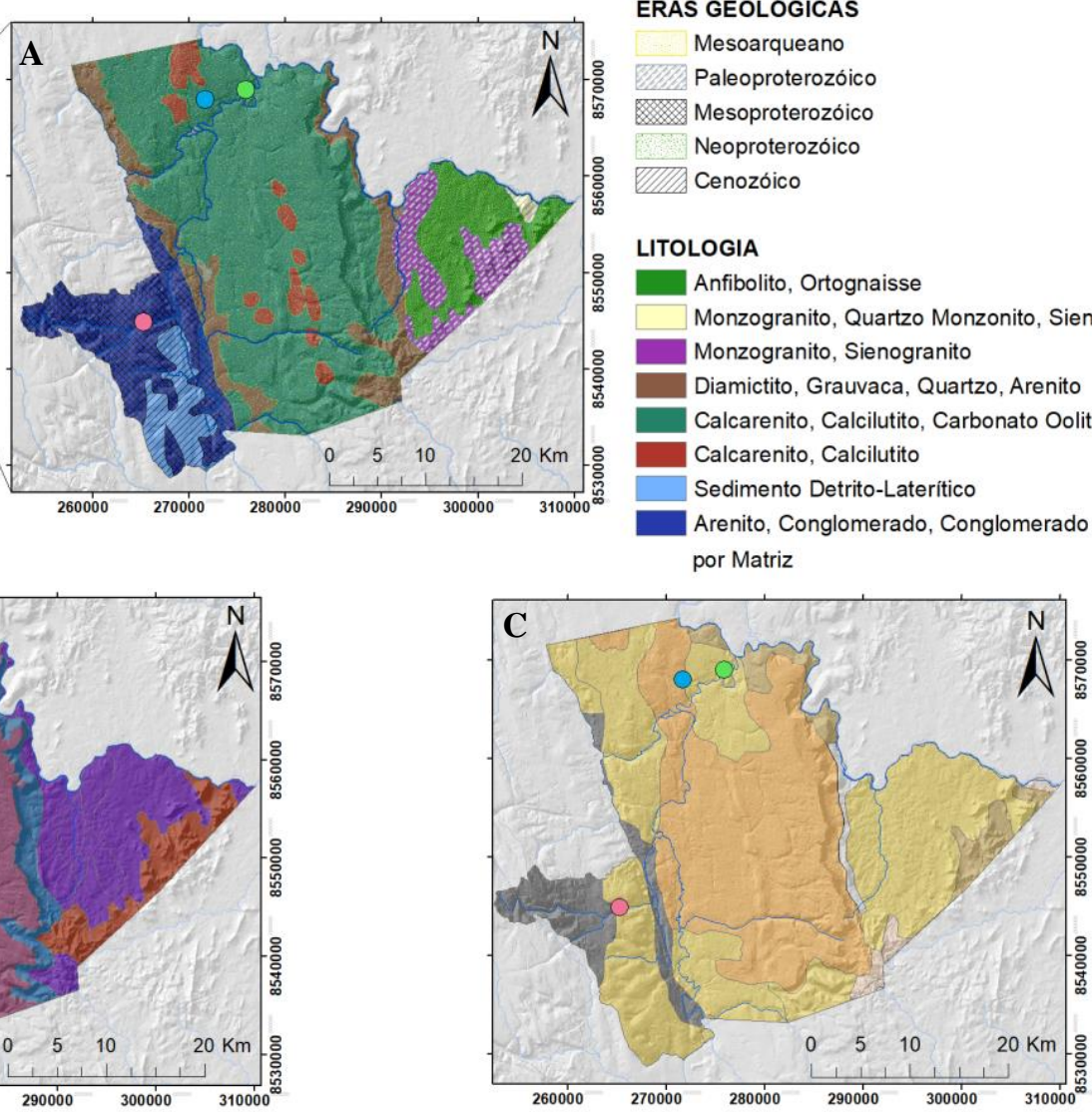

CLASSES DE SOLO

ARGISSOLO VERMELHO-AMARELO Eutrófico

CAMBISSOLO HÁPLICO Tb Eutrófico

LATOSSOLO VERMELHO Eutrófico

LATOSSOLO VERMELHO-AMARELO Distrófico

NEOSSOLOS LITÓLICOS Distróficos

NEOSSOLOS LITÓLICOS Eutróficos

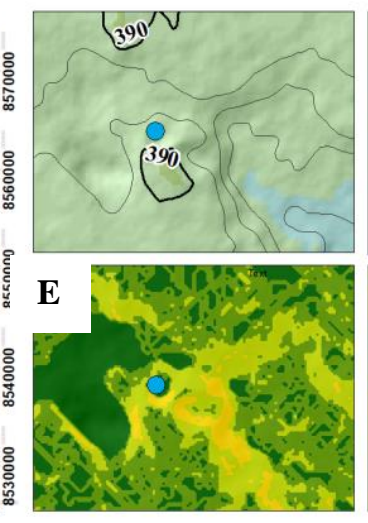

Rodovias

Hidrografia CURVAS DE NIVEL

- Primárias

Secundárias

(Equidistância vertical de $13 \mathrm{~m}$ )

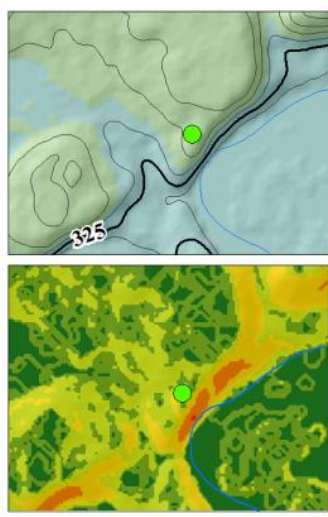

DECLIVIDADE
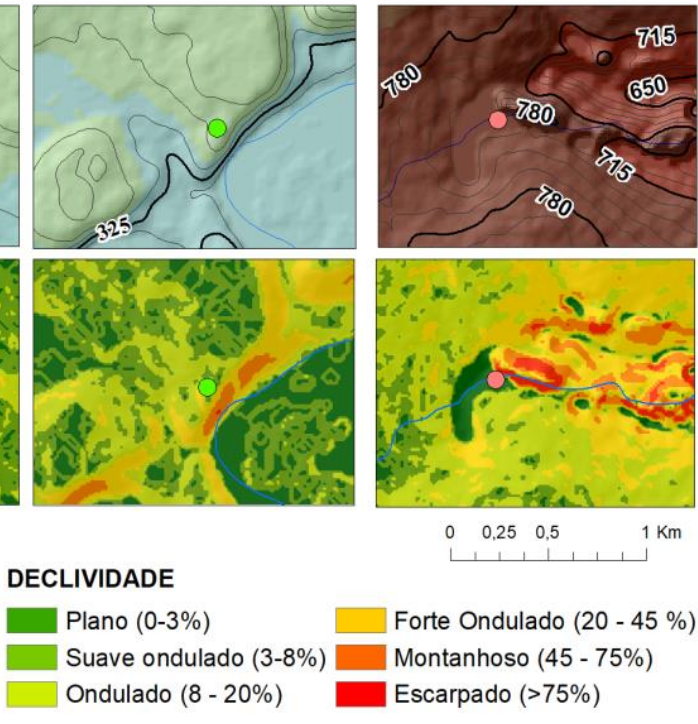

$\begin{array}{lll}0 & 0,25 & 0,5\end{array}$

$1 \mathrm{Km}$

Mapa de Elementos da Geodiversidade dos Geossítios

Caverna do Poço Encantado, Caverna da Lapa do Bode e Cachoeira Encantada, Município de Itaetê - BA

Projeção Universal Transversa de Mercator (UTM) Datum: SIRGAS 2000, Fuso 24 Sul

MDE: ALOS PALSAR (11/2010) - Alaska Satellite Facility (ASF)

Base Cartográfica: Instituto Brasileiro de Geografia e Estatística (IBGE)

fapesb 鵻

Elaboração: Ericka Silva (2020) 
Figura 1 - Mapas geoambientais dos geossítios inseridos no município de Itaetê. A - Mapa Geológico; B - Mapa Geomorfológico; C - Mapa Pedológico; D - Mapa Hipsométrico; E - Mapa de Declividade.

No município são identificados predominantemente os Latossolos Vermelho-Amarelos Distróficos, abrangendo a caverna da Lapa do Bode e a Cachoeira Encantada, e o Latossolos Vermelhos Eutróficos, que compreende a caverna do Poço Encantado (Fig. 1 $-\mathrm{C})$.

A comunidade do Poço Encantado, com em média 45 famílias, tem o turismo como principal atividade econômica. No entanto, passa por dificuldades devido a estradas de difícil acesso à comunidade, carência de rede telefônica, serviços de correio, posto de saúde e escola. Próximo à comunidade está o Assentamento Roseli Nunes, com 159 assentados, cuja principal atividade econômica é o cultivo da mandioca para produção de farinha, processada na "casa da farinha", administrada pela Associação das Mães, que fortalece projetos e aquisição de recursos para o assentamento. $\mathrm{O}$ assentamento oferece serviços de posto de saúde, uma unidade escolar de ensino fundamental e sedia a Brigada Federal de combate a incêndios na Chapada Diamantina. Próximo a Cachoeira Encantada está o Assentamento Baixão, com 140 famílias, a principal atividade econômica é a agricultura familiar, e tem investido também no turismo comunitário, com uma pousada comunitária para hospedar os visitantes.

Em síntese, o uso das geotecnologias apresentou-se fundamental para obtenção de informações sobre a geodiversidade das áreas de estudo e também possibilitou agregar com elementos necessários para o inventário dos geossítios. O diálogo e a troca de informações com os moradores permitiu a divulgação da importância patrimonial destes sítios, também como coletar informações para elaboração de propostas para possibilitar seu uso sustentável e conservação.

\section{REFERÊNCIAS}

BRILHA, José. A Rede Global de Geoparques Nacionais: um instrumento para promoção Internacional da Geoconservação. In: SCHOBBENHAUS, Carlos; SILVA, Cassio Roberto da (Org.). Geoparques do Brasil: propostas. Rio de Janeiro: CPRM, 2012. Cap. 2

CPRM - Companhia de Pesquisa de Recursos Minerais. Mapa Geodiversidade do Brasil. Escala 1:2.500.000. Legenda Expandida. Brasília: CPRM/Serviço Geológico do Brasil, 2006. P.68.

GRAY, M. Geodiversity: valuing and conserving abiotic nature. Londres: John Wiley e Sons Ltd, 2004.

PEREIRA, R. G. F. A. Caracterização geomorfológica e geoespaciológica do carte da Bacia do Rio Una, borda Leste da Chapada Diamantina (município de Itaetê, estado da Bahia). Dissertação de mestrado. Programa de Pós-Graduaçâo em Geoquímica e Geotectônica. São Paulo, $1988 . \quad$ Disponível em: https://www.teses.usp.br/teses/disponiveis/44/44134/tde-21102015-

155053/publico/Pereira_Mestrado.pdf. Acessado em:18 de nov. de 2019.

PEREIRA, R. G. F. A. Geoconservação e desenvolvimento sustentável na Chapada Diamantina. Tese de doutorado. Universidade do Minho (Portugal) - 2010. Disponível em http://repositorium.sdum.uminho.pt/handle/1822/10879, Visitado por última vez em: 18 de nov. de 2019. 